\title{
Chapter 6 \\ The Many Roads to an Ideal Paper-based Device
}

\author{
Margot Karlikow and Keith Pardee
}

The recent Zika and Ebola virus outbreaks highlight the need for low-cost diagnostics that can be rapidly deployed and used outside of established clinical infrastructure. This demand for robust point-of-care (POC) diagnostics is further driven by the increasing burden of drug-resistant diseases, concern for food and water safety, and bioterrorism, among many other necessities. As has been discussed in previous chapters, paper-based tests provide a simple and compelling solution to such needs. Paper-based tests and devices are themselves not new and in fact were first developed in the 1930s [1], but have only emerged recently as broadly capable tools for rapid diagnostics outside of laboratory settings.

The most widely recognized paper-based diagnostic is the home pregnancy test that came on the market in 1988 [2]. This one-step assay to assess urine for the pregnancy hormone human chorionic gonadotropin uses the chromatographic effect of paper to drive flow for the onboard immunoassay that underpins detection. While the pregnancy test has been a tremendous success, many other clinical needs require portable diagnostics that are similarly complex and sensitive and, in turn, this has given birth to a whole field dedicated to the development of paper-based, POC diagnostics [3]. Accordingly, the lateral flow assay concept has been extended to a wide range of infectious disease antigens, nucleic acid sequences, and illicit drugs from diverse sample types (e.g., sputum, blood, fecal, food).

In 2004, the Whitesides group developed the "POCKET immunoassay" [4], a microfluidic compatible immunoassay to bring enzyme-linked immunosorbent assays (ELISAs) to the field and resource-limited environments where such analytical techniques are not usually available. Three years later this was followed by another report, from the same group, that used patterned paper to create paperbased microfluidics for the simultaneous analysis of glucose and protein in urine [5].

\footnotetext{
M. Karlikow $\cdot$ K. Pardee $(\varangle)$

Leslie Dan Faculty of Pharmacy, University of Toronto, Toronto, ON, Canada

e-mail: keith.pardee@utoronto.ca
} 
These two papers laid the groundwork for new types of paper-based devices to meet the growing need for complex, yet portable, diagnostics. Most prominently this has included microfluidic paper-based analytical devices ( $\mu$ PADs) for the development of low-cost and portable devices.

Paper-based devices can be designed for diverse sensing purposes, but those for health-related POC applications have especially stringent regulatory guidelines, such as those laid out by Kettler et al. in a 2004 WHO white paper. Referred to as ASSURED standards (Affordable, Specific, Sensitive, User-friendly, Rapid and robust, Equipment-free and Deliverable) these guidelines have become a standard for the field and provide a framework for engineers and clinicians alike to develop safe and effective paper-based diagnostics [6].

The ultimate goal in the paper-based diagnostics field is the development of fully integrated devices, able to achieve sample-in answer-out processes. But in the quest for the ideal paper-based devices, many obstacles remain. Here we survey some of the most recent and innovative paper-based diagnostics and the technologies that surround them, in hopes of helping to define what would be an ideal device. Accordingly, we review the areas of ongoing tool development, such as sample handling and preparation, sensitivity, and signal amplification, to frame our discussion and share advances in the field. However, the sensing modality employed in a device in many ways defines the challenges along the developmental path. Therefore, we will often discuss tool development for paper-based devices using antibody-based detection and those using nucleic acid amplification separately. This will be followed by a discussion of key technical aspects that we believe will lead the future directions of POC diagnostics, and then look at how, as a community, the vision of low cost and accessible diagnostics can be realized.

\subsection{Sample Preparation}

Sample preparation is "the forgotten beginning" [7] and a major bottleneck for POC diagnostics [8]. A recent study compared 13 different commercially available or close-to-market POC devices and found that in more than half of them the sample preparation was not included [9]. Further, as late as in 2016, a review from Tang et al. highlighted the fact that most analyte extraction methods require either an external electrical power, an external pump, or multiple steps [10]. In POC settings, the processing of biological samples for diagnostics is a critical challenge complicated by the diversity and the intrinsic complexity of patient samples (e.g., blood, saliva, urine). These challenges begin with the sample collection and require the development of a workflow to separate, extract, and often amplify the analyte of interest for the paper-based diagnostic system. Each step needs to be considered as part of the whole workflow and in the context of sample, patient, and environmental factors [11]. Below we discuss each of the sample preparation steps and explore how engineering efforts are advancing sample preparation in the pursuit of the ideal paper-based device. 


\subsubsection{Collection of the Sample}

An ideal POC diagnostic would be free of the need for skilled personnel to operate and would provide results the same day, ideally during the same hour, obviating the need for collected samples to be stored. With these target features in mind, the sample collection modes to consider should be noninvasive procedures that can be performed by untrained or only semiskilled users.

\subsubsection{Blood}

Blood is the most clinically important diagnostic sample type due to the fact that it provides a rich source of molecular information that can be monitored by either antibody or nucleic acid-based approaches [12]. By far, the most widely used technique for POC blood collection is the finger stick, which uses a blood lancet for capillary blood sampling. The technique is widely used for monitoring blood glucose in POC settings and more recently has been used to explore among others early innate transcriptomic responses generated over time after vaccination [13]. Exciting work in this space also includes the demonstration that RNA quality and gene expression data obtained using finger stick collection correlates well with more conventional venipuncture [14], which suggests a strong future for robust nucleic acid analysis at the POC.

Skin chemistry is also a "window to body's health" [15] and can be used as a substitute of blood analysis. Indeed, serum-rich interstitial fluid in the dermis contains numerous biomarkers (glucose, creatinine, lipids, nucleic acids, proteins, urea, etc.). Moreover, as a protective barrier to our bodies, the skin hosts significant immunological machinery and, as such, is an excellent potential tissue for monitoring the state or history of the immune system and infection. Skin chemistry, however, has proven difficult to monitor because of the lack of convenient methods of sampling [15].

Fortunately microneedles have recently emerged as a method to sample skin chemistry. Initially developed for transdermal drug delivery [16-18] and glucose monitoring [19], Corrie and colleagues developed an innovative POC device for the monitoring of specific biomarkers from the serum-rich fluids of the upper dermis [20]. To do so they engineered chemically and mechanically modified microprojection arrays to selectively retrieve protein biomarkers from the skin. With this minimally invasive technique for sampling soluble markers, authors demonstrated the capture of anti-FluVax ${ }^{\circledR} \operatorname{IgG}$ in mice vaccinated with FluVax ${ }^{\circledR}$. More recently microprojection arrays have also been developed as a wearable patch for multiplexed sampling of biomarkers directly from the skin of mice [21]. 
While these devices are not paper based, they are portable and have the potential to enable low-cost diagnostics in the field. Importantly microprojection arrays also have the potential to further enable pain-free sample collection and may provide a method for integrating multiplexed sample collection to established paper-based diagnostic platforms. However, important challenges remain to be solved: factors such as (1) the time required to recover samples from the skin (which can take several hours for low-abundance biomarkers [20]); (2) the design of arrays, for instance, the depth at which targeted cell types are found varies between the gender and age of patients, and accordingly the thickness of arrays/projects must be properly calibrated to avoid sampling artifacts; and (3) the analyte type to be harvested by this method. Further, reports to date have been limited to protein-based antigens. Nucleic acid sampling with microneedles/microprojections could greatly improve the development of skin chemistry as a diagnostic target. Interestingly, the recovery and analysis of nucleic acids from microprojections were described in an early patent [22].

Taken together, advances in blood and interstitial fluid collection are beginning to enable the harvest of minute samples in a way that can be done by untrained individuals in settings outside of the lab for the sampling of both proteins and nucleic acids.

\subsubsection{Respiratory Samples}

Sputum is a thick, cloudy, and sticky sample coughed up from the lower airway that contains a mixture of mucus, with endogenous and exogenous components, mucin molecules, filamentous actin, elastin fibers, bacteria, cell debris, and DNA. It can be coughed up in a natural way or be induced by inhalation of steam, sterile saline, or glycerin aerosol. Importantly, sputum samples are not saliva samples, which contain large amount of oral bacteria [23] that can contaminate sputum [24]. This complex mixture is part of the immune system that functions as a natural barrier to infection and as such is an interesting fluid to study. The value of sputum as a diagnostic fluid has even been demonstrated through the monitoring of color changes that have been correlated with lung cancer, and bacterial or viral infections. A particularly relevant use of sputum samples in diagnostics has proven to be tuberculosis. Here nucleic acid-based POC tests have been developed for the detection of tuberculosis, efficacy of treatment, and determination of coinfection with HIV [25, 26] [27, 28].

\subsubsection{Other Sample Types}

There are many other sample types that can be collected from patients, including, among others, urine, tears, stool, and buccal samples. In many cases the disease involved is an important factor in determining the best sample. Urine, for instance, is one that is easily collected and has shown significant diagnostic value. One timely example of the use of urine is as a sample for molecular diagnostics of the Zika virus. 
The Zika virus has been found in blood plasma for only a median period of 10 days following infection and this has made the detection of the virus difficult for a disease where most patients are asymptomatic (Jean Michel [29]). Interestingly, Zika virus can be found in patient urine and saliva for as long as 30 days [30]. Whole blood (22 days) and semen (62 days) also appear to provide a greater diagnostic window for Zika virus than plasma [29, 31, 32].

Swab-based methods (e.g., skin and buccal) are another important means of collecting samples from patients [33]. Swabs are often used in lateral flow POC tests for respiratory infections such as influenza and streptococcal antigens (e.g., Strep test). While most tests require swabs to be eluted, shaken and pipetted on the device (like the Alere BinaxNOW RSV), a recent paper from the Yager lab reports a nasal "swab-to-result" device for diagnosis of two strains of influenza with an average time to result of $35 \mathrm{~min}$ [34].

As the field of POC diagnostics moves forward, there is great opportunity to probe some of these less frequently considered sample types as well as exploit pathogen physiology by selecting fluids enriched in the telltale signs of target infections. Regardless of sample type, once collected, crude samples are often too complex for direct analysis. To remove interfering agents or background, and obtain a better sample to analyze, a separation step is often required as part of sample preparation. At the POC, this can be a challenging operation and one that, while often neglected, is starting to see real progress.

\subsubsection{Separation}

\subsubsection{Blood}

Blood plasma, which makes up about $55 \%$ of whole blood, is extremely rich in proteins, nucleic acids, ions, and molecules, making it an invaluable target for diagnostics. However, red blood cells constitute the majority of the remaining blood volume and this complicates the separation process. If not correctly and carefully removed, red blood cells can clog, rupture, block, and foul a diagnostic device and the subsequent assay. Under laboratory conditions, blood samples are easily processed at $4{ }^{\circ} \mathrm{C}$ and centrifuged to isolate the plasma fraction without clotting. In the field or at home, the task of separating the plasma is decidedly more challenging and as a result POC blood separation techniques have fallen behind that of other sample types.

That said, there are some exciting innovative approaches that are extending the preparation of plasma from whole blood to field environments. Liu and colleagues [35] developed a plasma separator that allows the isolation of plasma from undiluted blood. This technique however requires almost $2 \mathrm{~mL}$ of blood to extract $300 \mu \mathrm{L}$ of plasma and, as a result, a trained individual is needed to collect the sample. More recently a low-volume $(2-4 \mu \mathrm{L})$ microfluidic on-chip blood separation device compatible with finger stick collection has been developed that, when compared to 
off-chip separation, recovers $90 \%$ of the proteins and $100 \%$ of the nucleic acids from whole blood [36].

Microdialysis has been another important method for POC blood separation. The approach uses nanofiltration, where the molecular weight cutoff of the membrane is used to selectively concentrate a wide range of targets [37-39]. However, several challenges like membrane fouling and clogging persist [40], and pressure- or voltage-driven mechanisms, among others, are still needed for devices to work. Byrnes and colleagues recently demonstrated the use of passive lateral flow and anion-exchange chromatography to simultaneously purify and concentrate DNA from samples with high protein content or blood, using porous membranes coated with chitosan [41]. While in their study membranes clogged at concentrations of below that of whole blood, they demonstrated that on-site dilution of patient samples would be a simple and easily implemented solution. Using an orthogonal approach, D'Amico and colleagues developed a microfluidic membrane-less technology to isolate and concentrate bacteria from whole blood [42] based on their dielectrophoretic behavior compared to red blood cells.

\subsubsection{Urine (and Other Secreted Fluids)}

In the case of secreted fluids like urine, tears, or sweat, there can be a need to concentrate target molecules before diagnostic analysis. A simple concentration method based on evaporation and passive pumping was developed by Walker and colleagues using microfluidics [43] where they used evaporation-induced flow to concentrate beads (pathogen proxy) and fluorescently labeled BSA. This concept was recently extended by using heat and the high surface area of paper to augment evaporation for the concentration of analytes in urine [44]. This creative approach was effective at a 20-fold concentration of a urine biomarker (TB-related glycolipid lipoarabinomannan) and it would be interesting to know if a similar approach could be used to concentrate nucleic acids. With longer biopolymers like DNA/RNA it might be possible to capture target molecules at the inflow edge, rather than at the site of evaporation, by essentially using a filtering or chromatography effect.

Another exciting approach for the concentration of diagnostic analytes has recently been demonstrated using digital microfluidics (DMF, [45]). DMF is a fluidhandling technique that uses electrical charge to move aqueous droplets around on Teflon-coated electrodes (a more detailed description of the potential for DMF is developed later in this book chapter). As a tool for analyte concentration, Choi and colleagues used DMF to perform solid-phase microextraction (SPME) of steroid hormones from urine. SPME fibers coated with C18 silica particles selectively concentrated the steroid from the complex sample matrix, allowing detection with downstream mass spectrometry analysis. While in this case DMF was not coupled to POC diagnostics, the technique does offer an interesting and potentially economical means of performing complex sample preparation in the field. 


\subsubsection{Sputum}

Due to its nature, isolation of analytes from sputum samples is perhaps the most challenging of the possible matrices and yet, as we discussed, it is an important noninvasive source of diagnostic material. Laboratory-based processing of sputum samples for diagnostics involves chemical (mucolytic agents) or mechanical (sonication, vortexing) liquefaction prior to nucleic acid tests [46]. Very few portable systems have yet to be developed for mucus separation and sample extraction. One exciting example is the Cepheid GeneXpert technology that uses an automated cartridge for the ultrasonic lysis of organisms like Mycobacterium tuberculosis captured in a filter. This is followed by PCR-based detection of the pathogen and determination of rifampicin resistance [25, 47]. However the cost of the Cepheid Xpert instrument is not trivial, with a unit cost of at least \$17,000 USD [48, 49]. A Phase I SBIR clinical trial has also recently been reported for the development of a new automated POC cassette for processing of sputum samples for nucleic acid extraction; however, the associated costs have yet to be reported (https://www.sbir. gov/sbirsearch/detail/706169). A recent study offers a potentially more accessible and minimally instrumented approach. Here sputum is disinfected and liquefied and then pathogen is mechanically lysed using a battery-operated bead beater. Using this approach DNA could be isolated for qPCR (or POC diagnostics) from spiked TB cultures in under $10 \min [26]$.

\subsubsection{Extraction}

As described above, each sample type requires a tailored method for separation of the pathogen from the surrounding matrix. This effort must then be paired with an appropriate extraction step for the analyte of interest. In the lab there are many tools at our disposition to isolate the target proteins and nucleic acids from these matrices. These include mechanical (e.g., grinding, douncing, or even bead beating), thermal, or chemical methods (e.g., detergent, chelating agent, proteases). The resulting lysate is then often subjected to physical (e.g., centrifugation), chemical (e.g., phenol/chloroform), or a solid phase-based separation (e.g., nucleic acid column). Of course, these conventional methods of extraction are generally not well suited for use in the field where specialized equipment and skilled technicians may not be available. The POC diagnostics field, fortunately, has been focused on adapting many of these laboratory methods to field-appropriate techniques [50].

\subsubsection{Heat}

In a POC context, heat may be the simplest approach for nucleic acid extraction from pathogens. Boiling water is something that is almost universally available and a simple 40-s boiling water bath has been demonstrated to release cellular contents 
without damage to nucleic acids [51]. Similar results have been reported for the lysis of virus [52-54]. Often the thermal lysis of pathogens is sufficient and lysates can be loaded directly into the diagnostic workflow or analytical device. For example, the thermal lysis of bacterial cells in PCR buffer, followed by PCR amplification and sizing, was performed on a reusable chip in 1998 [55]. More recently, extraction and isolation of Vibrio cholerae from fecal samples were performed using solar-thermal energy. Here, without the need of external electrical power, a stable temperature of $95^{\circ} \mathrm{C}$ was achieved in less than $5 \min [56]$.

\subsubsection{Enzymatic/Chemical}

Enzymatic and chemical hydrolysis of capsids, cell walls, and membranes is used routinely in the lab to extract analytes from samples. Some of the most commonly used enzyme-based approaches are proteases or lysozyme, which are highly effective but do have limitations for POC applications when pathogen identity is not known. For example, in the case of lysozyme, some bacterial species (e.g., Staphylococcus sp.) have evolved resistance to the glycoside hydrolase in response to the enzyme's role as an antimicrobial in the innate immune system [57]. An interesting alternative without this limitation is the bacteriolytic enzyme achromopeptidase (ACP; [58, 59]). As with other proteases this enzyme can cause problems with downstream nucleic acid amplification reactions; however, ACP activity is labile to heat $\left(>80^{\circ} \mathrm{C}\right)$ so can be easily inactivated, allowing for subsequence molecular steps to be done without purification of nucleic acids. Importantly, ACP is stable dry-stored for easy POC distribution [60, 61].

Chemical hydrolysis of pathogens (e.g., alkaline lysis, detergents, organic solvents), while also very effective at extraction, comes with their own limitations as they must often be neutralized, removed, or diluted so as not to impede downstream analysis. Such additional complexity and potential point of failure is not an ideal scenario for POC applications [52]. Whatman FTA papers, which have lytic reagents embedded, may provide a more simplified workflow, but their use still requires extended washes to remove lytic agents before downstream molecular steps.

To address the challenge of lytic agents, Schilling and colleagues demonstrated continuous chemical lysis of bacteria in a pressure-driven microfluidic device that also performed separation of lysed versus non-lysed debris and optical detection [62]. To develop this system they used passive diffusion and formularized flow patterns and pump rates to monitor the fluorescence emitted by a fluorogenic enzyme when cells where lysed. Intact cells were sorted due to the flow rate and their inability to diffuse at the correct location in the device for detection. Similarly, Byrnes and colleagues have recently reported the development of a pressurecontrolled device called SNAP (the system for nucleic acid purification) for nucleic acid extraction from whole blood mixed with a lysis buffer, at ambient temperature, in an enzyme-free manner without electricity [63]. The eluted samples yielded qPCR-compatible nucleic acids without any subsequent purification. Impressively, 
their device performed extraction of HIV-1 viral RNA from virions in whole blood in less than $35 \mathrm{~min}$.

Another interesting alternative has been developed by the Keso lab, called filtration isolation of nucleic acid (FINA), which allows DNA extraction from whole blood lysed using the surfactant Triton X-100 (1\%) in less than 2 min. Here authors carry out lysis on a Fusion five membrane (Whatman Inc.) that is backed with blotting paper to draw material through. Comprised of glass oxide fibers, the membrane has high affinity for DNA and thus serves as a capture agent to allow simple processing steps. Once lysed, the coated membrane is rinsed with $\mathrm{NaOH}$ to remove inhibitory proteins (e.g., hemoglobin). The residual $\mathrm{NaOH}$ does not inhibit downstream steps and so the DNA-bound membrane can be transferred directly to qPCR for analysis. Authors have demonstrated this approach in processing HIVcontaining blood samples, where it has yielded sensitive and specific results for the detection of the virus [64-66]. Cost, however, of this approach is likely a limiting factor for global health applications, with an estimated price \$50 USD/test and $\$ 3000$ USD for the analyzer. Nonetheless, the technical concepts demonstrated with this and the two previous methods are compelling and hold significant potential for incorporation into lower cost paper-based devices.

\subsubsection{Mechanical}

Mechanical lysis uses force to burst cells and has been used to create some interesting options for analyte extraction. One clever design has used sharp nanoscale barbs in a microfluidic system to perform efficient lysis of cells without contaminating the sample with additional chemicals [67]. Here, using different microfluidic designs, flow and pressure of the sample can be increased or decreased without any external power. Another device, which has been commercialized, uses bead shearing/beating for rapid lysis of bacteria in small static volumes $(<80 \mu \mathrm{L})$ or larger volumes $(1 \mathrm{~mL})$ in continuous-mode bacteria preparation [68]. Sold by Claremont BioSolutions, the device boasts excellent rates of lysis (>90\%, $30 \mathrm{~s})$ and has been used in a number of recent diagnostics-related publications [26, 69]. Each homogenizer is available for as little as $\$ 6.90$ and is designed for single use [70].

Other mechanical disruption options are available, including the sonicationbased approach used by GeneXpert described above for processing of sputum. The prototype for this minisonicator was first demonstrated with highly resistant spores from Bacillus and reported an optimal disruption for PCR analysis in only $30 \mathrm{~s}$. The combined sample preparation and PCR identification were done in an impressive $15 \mathrm{~min}$ [71]. While these mechanical methods of disruption are stunning, they come at a cost (Claremont BioSolutions: \$7; GeneXpert: \$16.86) that may be a limiting factor for global health applications $[48,49]$ and perhaps even for domestic applications.

To address the hardware and/or consumable costs associated with mechanical disruption, there have been some clever solutions that combine microfluidics with chemistry-based extraction of nucleic acids. Baier and colleagues developed such 
a hand-free sample preparation device for nucleic acid analysis from cervical fluid for HPV diagnostics. The two-stage, credit card-sized device first concentrates cells and then extracts HPV-mRNA for an isothermal amplification-based detection [72]. Microfluidic origami also offers an exciting low-cost extraction option for use in remote settings. Here chemistry-based lysis is merged with a folded paper device that is operated by sequentially bringing taps together to process complex samples. The device was able to extract DNA from samples with as little as 33 bacterial $\mathrm{CFU} / \mathrm{mL}$ from simulated sputum for an estimated cost of about \$2 USD. Sample processing did take between 1 and $1.5 \mathrm{~h}$, with or without heat, respectively, but the device is nonetheless compelling for many applications in global health [73].

\subsubsection{Electrical}

Electrical fields can also be used to induce lysis in diagnostic samples. This approach takes advantage of a well-studied phenomenon where high-strength electric fields $(\mathrm{kV})$ can induce significant change in cellular membranes, leading to the formation of transient holes [74]. This effect has been used in a process called electroporation for the loading of cells with DNA or pharmacological substances $[75,76]$ and at higher electrical field strengths can be used to effectively kill/lyse microorganisms (99.99\%; [74]). This lysis method has the advantages of no moving parts or the addition of reagents to samples. Moreover, the field value for cell lysis is dependent on the cell type (e.g., bacteria, fungi, and mammalian) and thus can be used for the selective lysis of cells.

Early attempts at the electrolysis of cells required substantial voltage in microfluidic systems (1400 V) [77]. However, with the incorporation of direct current and small, modified channel geometry voltage, the requirements for electrolysis have been reduced to a scale that can be delivered in the field by small batteries (e.g., $2-50 \mathrm{~V}$ ) [78-80]. The potential to precisely localize electrolysis has also been exploited for diagnostics. While most lysis methods release analytes into bulk solution, which leads to dramatically lower concentrations for diagnostic assays, Besant and colleagues recently developed a device for the electrolysis of bacteria at a minimal distance to the site of detection [81]. To do this, authors built nanoscale compartments $(1 \mathrm{~nL})$ where cells were electrolyzed directly in next diagnostic sensors, enabling high local mRNA concentrations at the detector.

While these methods for electrolysis are currently too technical for low-cost POC deployment, they offer food for thought on what might be possible. Paper can be made conductive with the use of printable conductive inks [82], which have already been used to create paper diagnostics with electrochemical outputs [83, 84] and paper-based batteries [85]. So with a goal of looking toward an ideal paper-based device, it is exciting to think about the potential for printable all-in-one devices, with no moving parts, that could carry out both automated electrolysis and electrochemical sensing. 


\subsection{Overcoming Challenges in Sensitivity and Specificity}

For low-cost portable diagnostics to have a meaningful impact on public health, they must incorporate high sensitivity and specificity. These requirements are highlighted by the WHO's ASSURED criteria. However, due to constraints on cost, time, size, and complexity, portable diagnostics often provide lower performance than labbased counterparts. This fortunately is starting to change as paper-based diagnostics are beginning to extend lab-grade capabilities out into the world with detection thresholds in the low femtomolar to attomolar range [54, 69, 86].

Sensitivity refers to the threshold of detection for an analyte. For POC diagnostics an ideal device is able to identify target molecules directly from samples without concentration. Accordingly, sensitivity is consistently listed as a top priority for portable tests, and while improvements are being made a recent survey of POCs for sexually transmitted diseases highlighted that many tests lack the sensitivity needed to be useful in practical application [87]. Specificity is the measure of the rate at which devices report the correct results and is similarly of great importance because of the implications for false diagnosis. The ideal rate of specificity accordingly is $100 \%$. These two features, sensitivity and specificity, often work against each other as is seen in the reciprocal effect observed between lateral flow speed and sensitivity [88] (Millipore). While challenging, the development of tools with high sensitivity and specificity is critical to extending the reach of lab-grade diagnostics globally and has tremendous potential for public health.

How diagnostic sensitivity and specificity can be achieved is very dependent on the mode of detection. For instance, in the case of sensitivity, antibody-based diagnostics need to accommodate the nature of protein-based analytes that are not easily replicated and thus generally rely on post-detection amplification. Conversely, nucleic acid-based diagnostic strategies generally involve amplification of target sequences and thus provide signal enhancement as part of the assay. For many applications, providing clinically relevant sensitivity in either of these modes will likely require the inclusion of simple equipment into the diagnostic workflow. Over time, we anticipate nanomaterials and molecular technologies to fulfill these current equipment-dependent roles to ultimately provide ideal devices that are truly equipment free.

\subsubsection{Antibodies: Signal Amplification}

The need for greater sensitivity in antibody-based diagnostics has been met through strategies that rely on first detecting the analyte and then the use of enzymes, metal ions, or nanoparticles to amplify the output signal from the assay reaction. Within these signal amplification modes there has been a wide range of techniques developed. 


\subsubsection{Enzymes}

The first of these, enzymes, have a long history of application as sensors in diagnostics; perhaps the most widely recognized enzyme in POC diagnostics is glucose oxidase for the measurement of blood sugar [89]. However, enzymes are now also being used to amplify the signal from antibody-based detection of analytes. Examples of such enzyme-based amplification include the use of enzymes like horseradish peroxidase (HRP) [90] and alkaline phosphatase [91] to catalyze the generation of optical signal outputs from tests. An exciting new application of HPR signal enhancement was recently reported where the enzyme was used to deposit polydopamine for a high-contrast color-based signal. In HIV p24 lateral flow assays, this technique provided authors with a 1000-fold increase in signal detection [92].

The use of enzymes for signal amplification of course raises the issue of longterm stability of protein-based reagents for distribution to remote locations. In many cases, freeze-drying with cryoprotectants enables such use, but importantly recent advances have also aimed to tackle more challenging enzymes. In one report, the Yager lab demonstrated the long-term dry storage of the enzyme HRP by combining the cryoprotectant trehalose with $\mathrm{FeSO}_{4}$ [93] and in a second approach, from our own lab, showed that antibody-enzyme conjugates could be manufactured on-site using a freeze-dried cell-free expression system [94].

\subsubsection{Nanoparticles}

The use of particles and nanomaterials has also proven to be effective in signal amplification for antibody-based assays. These materials include metal and silica nanoparticles [95-97], functionalized latex particles [98], magnetic particles [99, 100], quantum dots [101], and carbon nanomaterials [102], among others. Of these, gold nanoparticles (AuNPs) have a number of features that make them especially well suited to POC diagnostics, and accordingly have become widely used. AuNPs are very stable, which enables distribution and storage either in solution or in a dry powder and, despite the value of gold material itself, only extremely small amounts of the AuNPs are needed for detection. Gold nanoparticles are also easily functionalized with antibodies and other biomolecules and do not fade with exposure to light $[103,104]$. Most importantly however, AuNPs have unique optical and electrical properties that make them useful as both visual and electrochemical outputs for diagnostics. The optical properties of AuNPs include a deep color that ranges from deep red to blue, depending on their diameter, that allows for diagnostic outputs to be read directly by the naked eye [103, 105]. For electrochemical assays, antigen-antibody interactions can be used to recruit AuNPs to electrodes, which augments the conductivity of electrode surfaces for diagnostic detection [106].

The most conventional use of AuNPs in diagnostics is as part of a "sandwich" immunoassay in a lateral flow device, where target antigen is first captured by a target-specific antibody and then probed by a second antibody conjugated to AuNPs. These colorful/electro-active nanoparticles serve as labels that allow users 
to track molecular interactions occurring at the surface of the paper device with the naked eye or companion electronics. In such lateral flow assays, positive results are usually indicated by the formation of a band or dot next to a positive control [95, 107]. Despite success of diagnostics like the pregnancy test, for many applications antibodies may lack the sensitivity for detection at clinically relevant concentrations [95].

Fortunately, the limit of detection (LOD) for these AuNP-labeled interactions can be enhanced in a number of ways. Enzymes, such as HRP, have been used to amplify the AuNP signal. In such applications, once target binding has occurred, colorimetric enzyme-substrates are added and enzyme activity yields a color change that augments LOD. This strategy has been reported to provide tenfold improvement in sensitivity [108, 109]. While helpful, limited enzyme stability and need for the construction of complex conjugates (e.g., AuNP + antibody + enzyme) could potentially pose challenges for real-world POC diagnostic applications [105].

Metal ions offer an alternative method for signal enhancement. Silver and gold ions have been used to increase the size of nanoparticles and in doing so increase the visual target for the diagnostics user. Silver enhancement takes advantage of autometallography, a process where donated electrons induce the reduction of silver ions to metallic silver [110]. In the mid-1980s, this method was used to increase the observable size of antibody-conjugated AuNPs for electron microscopy [111]. Building on this concept, silver enhancement was incorporated 5 years later in lateral flow devices where it can provide an increased LOD of 50- to 100-fold [112, $113]$.

\subsubsection{Nucleic Acids: Signal Amplification}

With the goal of extending the reach of lab-based clinical diagnostics to the POC, efforts toward truly portable and low-cost nucleic acid amplification tests (NAATs) are some of the most exciting. These techniques are approaching, or in some cases already achieving, $100 \%$ specificity and are increasingly available for patient care and surveillance of infectious disease in global health [100,114]. As we will discuss, NAATs have a surprising range of diversity in their design and similarly provide variable sensitivity and specificity.

\subsubsection{Isothermal Amplification}

Polymerase chain reaction (PCR), the most common lab-based method for NAAT diagnostics, is a powerful technique that allows for the detection of minute amounts of specific nucleic acids through a series of amplification reactions that require thermal cycling. While it would be ideal to deploy PCR to POC settings for diagnostics, this task comes with significant challenges. PCR is expensive and 
requires specialized equipment, laboratory infrastructure, and skilled technicians, all of which are often limited at POC settings. As a result, patient samples are generally shipped for PCR tests in clinical labs, often leading to delayed reporting to patients [115].

There has been tremendous effort invested into moving this capability to the POC and much of this work has focused on the development of alternative isothermal nucleic acid amplification methods. As the name suggests, these amplification reactions operate at a single temperature, rather than thermal cycling, and as such do not require sophisticated equipment. In fact, heating for these reactions can even be provided using a chemical heater (e.g., calcium oxide and water reaction) [116]. Other benefits of isothermal methods include a simplified workflow, meaning that work can be done outside of the lab by individuals with little to no training [117]. Commercial isothermal reactions have recently become available and with these isothermal amplification of nucleic acids has begun to appear in paper-based formats $[118,119]$. In this section we review isothermal amplification mechanisms and some of the ways that they have been coupled to paper-based diagnostics. For a complete review on this topic please see an excellent review by Craw and Balachandran [120].

NASBA, or nucleic acid sequence-based amplification, is an isothermal amplification developed in 1991 by Jean Compton at Cangene [121]. This non-cycling nucleic acid amplification method involves three enzymes and two primers, and works in two steps: (1) initial denaturation and primer annealing at $65{ }^{\circ} \mathrm{C}(2 \mathrm{~min})$ followed by (2) nucleic acid amplification at $41{ }^{\circ} \mathrm{C}$ (>30 min). This method has been shown to have comparable sensitivity to RT-PCR [122] and was recently incorporated into the workflow of some of our paper-based diagnostics for the Zika virus where we found that the $65{ }^{\circ} \mathrm{C}$ step could be omitted [54].

Loop-mediated amplification assay (LAMP) was developed by Thai and colleagues in 2004 during the SARS coronavirus crisis and is one of the most commonly used isothermal amplification methods. In their seminal paper, they demonstrated high sensitivity $(100 \%)$ and specificity $(87 \%)$ when compared to reverse transcription PCR (RT-PCR) of viral RNA. While LAMP requires a constant operating temperature of $60-65^{\circ} \mathrm{C}$ it has been developed as a POC diagnostic. This includes Liu and colleagues' work [123] who developed a single-chamber cassette for HIV detection. The cassette used a FTA membrane for isolation, purification, and concentration of the nucleic acids for amplification with RT-LAMP and detection in less than $1 \mathrm{~h}(\sim 10 \mathrm{HIV}$ particles). More recently, Rodriguez et al. extended LAMP to a paper-based method that enabled extraction of clinical nasopharyngeal samples, isothermal RNA amplification (RT-LAMP), and detection of the influenza A (H1N1) all on the same piece of paper [124].

Helicase-dependent amplification (HDA) and recombinase polymerase amplification (RPA) are two other popular isothermal amplification methods. HDA uses DNA helicases in place of high temperatures to generate the single-stranded DNA templates necessary for primer hybridization. The HDA reaction yields new dsDNA that are then also bound by helicases for the cycle to repeat [125]. RPA is an increasingly popular, easy-to-use isothermal amplification method that is both fast (5-30 min) and sensitive. Working at $37^{\circ} \mathrm{C}-42^{\circ} \mathrm{C}$, this method uses three enzymes 
and a pair of primers to isothermally amplify DNA and can be extended to the detection of RNA by simply adding reverse transcriptase to the reaction. In the original paper RPA is used to detect methicillin-resistant Staphylococcus aureus [126] and has since been extended to the detection of a wide range of pathogens (viruses, parasites, bacteria) [127-129]. For a complete review on the use of RPA for diagnostics, please see Daher and colleagues' recent work on the subject [130].

The development of these isothermal methods represents a remarkable advancement in the development of portable and convenient field-ready nucleic acid tests. However, despite this success, there is still room for improvement of these reactions. Perhaps the most important challenge is that these methods are susceptible to contamination, which can yield off-target products and false-positive results [131]. As we will discuss below, one strategy to address this shortcoming is to add a second sequence-specific step to the detection process.

\subsubsection{Synthetic Biology}

As we have just discussed, isothermal amplification underpins most POC NAATs and, with ongoing innovation in this area, this trend can be expected to continue well into the future. However to address some of their limitations, other molecular tools are also being brought to bear in an effort to increase sensitivity, improve specificity, and add new molecular capabilities. Recent work from the field of synthetic biology has contributed to this effort. This includes work of ours, and that of colleagues, with the development of a paper-based diagnostic platform that operates using an isothermal transcription and translation reaction. The approach uses a new type of riboregulator, called a toehold switch, as a diagnostic RNA sensor. The necessary enzymes and DNA encoding the toehold switch are embedded into paper and freeze-dried to allow storage and distribution without refrigeration $[132,133]$. The freeze-dried paper device is activated by rehydration and the toehold switch DNA is transcribed to form an RNA hairpin at the $5^{\prime}$ end of a reporter mRNA. In the presence of target RNA, the hairpin of the toehold switch becomes linear, which allows ribosomes to bind for the translation of a reporter enzyme. Here the translation of the $\beta$-galactosidase enzyme catalyzes a visible color change on the paper in as little as $20 \mathrm{~min}$ after rehydration. As part of the proof-of-concept work, diagnostics for the strain-specific detection of the Ebola virus (Zaire vs. Sudan) and antibiotic resistance were demonstrated.

While this new capability was exciting, it lacked the sensitivity necessary to meet real needs in the field and so efforts turned to increasing the detection threshold of the system. This led to a follow-up work in May 2016 that reported a portable molecular diagnostic for the Zika virus [54]. The similarity between Zika and Dengue viruses causes cross-reactivity in serological assays for patient antibodies and so, with the outbreak in Latin America, there was great need for a portable molecular diagnostic for the virus. To solve the challenge with sensitivity, isothermal amplification was added in the workflow upstream of the toehold switch. By combining isothermal amplification with the toehold switch, not only was 
there an increase in signal amplification and sensitivity, but importantly this also addressed the general problem of false positives for isothermal amplification. In this configuration the detection of isothermal amplification products is now contingent on the second sequence-dependent toehold switching event for a paper-based color change.

As with isothermal amplification methods, toehold switch design is rational and can be done rapidly using an algorithm that selects regions of pathogen's genome with low secondary structure and that are unique from closely related pathogens and the human genome. Toehold switches are able to tolerate up to $11 \%$ mismatch in base pairing, yet the above computational selection of targets ensures no homology with off-target sequences [54]. This is an important feature that accounts for the constant evolutionary drift in pathogen genomes, meaning that toehold switches designed for first sequenced American strain of the Zika virus (2016) are also, in theory, capable of detecting all strains of the virus since its discovery in 1947 while still distinguishing from closely related Dengue virus isotypes.

This molecular capability was paired with a low-cost, battery-powered electronic reader to facilitate quantification in the field. When combined, the system was able to detect Zika virus at clinically relevant concentrations (2.8 femtomolar) from viremic plasma. Further, a combination of NASBA and CRISPR/Cas9 cleavage was used to discriminate between strains of the Zika virus with single base pair resolution at the POC [54]. Having demonstrated these paper-based Zika diagnostics with live virus and infected plasma, work is continuing in a patient and field trial in Latin America to solve the challenges of deployment. Follow-on work by the Collins and Zhang labs has further extended these capabilities with new work that relies on a different Cas protein. The system called SHERLOCK for "Specific High Sensitivity Enzymatic Reporter UnLocking" was demonstrated with the identification of the Zika and Dengue viruses, pathogenic bacteria, and SNPs in the human genome [69].

Synthetic biology has also developed many cell-based sensors for applications such as heavy metal or pesticide detection [134]; however for the most part these tools have not been translated into practice because of concerns over biosafety and challenges with getting efficient transport of analytes into cells [135]. A recent paper has incorporated brewer's yeast into a paper-based dipstick that can be used with patient samples, such as blood and urine [136]. Ostrov et al. achieved this by engineering extracellular G-protein-coupled receptors on the surface of yeast to sense peptides from human, plant, and food fungal pathogens. Spotted onto paper and dried for storage, these yeast cells turn a bright orange color in response to target pathogens. While work remains to translate these sensors to practical applications, one of the most exciting aspects of this work is that this is a self-replicating diagnostic that could provide very-low-cost diagnostics in global settings. 


\subsection{Equipment-Free Diagnostics}

One of the most debated elements of POC devices relates to its instrumentation. The ASSURED features suggested by the WHO were developed as general guidelines to assist in the development of ideal POC devices. Among those criteria, "E" indicates equipment-free devices. However, should we really exclusively focus on developing non-instrumented devices?

The call for equipment-free diagnostics is a compelling and rational goal for global applications where resources are limited (at home or in the field for example). Such designs will help to ensure robustness and low cost. Further, in POC environments with potentially limited access to electricity, it does make sense to strive for autonomous devices that are not reliant on electrical power infrastructure. This argument also extends to communities with limited or no access to smartphones with cameras. However, such scenarios are growing less, not more, common. Electric grids are becoming more reliable and in remote regions solar power, other renewable energy sources, and battery technologies are increasingly available [137, 138]. Similarly, mobile phone access is growing exponentially. There are currently over 5 billion unique mobile phone subscribers globally and this number is expected to grow by another billion in the next 5 years, and much of this growth is expected in developing regions where concern over access originally prompted the call for equipment-free diagnostics [139, 140].

Accordingly, we advocate that the equipment-free goal should be a longer term target and that providing portable, lab-grade sensitivity and specificity is most critical and should take precedence. Over time these capabilities will be progressively extended to locations with greater logistical challenges. Urbanization has brought large populations into cities where power is available [137, 141], although perhaps sporadically, and the resources are available to enable diagnostics with minimal equipment requirements. Urban populations are in great need of accessible diagnostics outside of hospitals, and we would argue that such applications can help to catalyze the long-term aspiration of complete independence from equipment. At home or in the clinician's office, this same minimal equipment-based approach for POC diagnostics would satisfy a significant unmet need in the near term and similarly drive the improvements necessary for truly equipment-free tools, where needed.

A recent paper from the Yager and Lutz labs does a great job of striking a balance between the need for equipment and the goal of equipment-free diagnostics by combining the necessary functions into a single-use cartridge [142]. Fitting within the equipment-free mandate, their system, called the multiplexable autonomous disposable nucleic acid amplification test (MAD NAAT), does not require skilled users nor rely on a smartphone for delivery or transmission of results. Other important features include a simple design where only a few manipulations are required by the user, the energy to perform the nucleic acid amplification comes 
from batteries within the cassette, and the device provides a simple yes/no answer. This is an exciting step toward equipment-free diagnostics and a trend that is reflected by other recent commercialization efforts.

But of course, not all clinical needs are compatible with a "yes/no" answer. Features such as quantification and test multiplexing are important milestones on the path to the ideal device $[11,143]$. So while the field may be on the verge of equipment-free solutions for applications of yes/no answers, the incorporation of simple equipment will likely be important in meeting many other clinical needs at the POC. With the rise of Arduino, Raspberry Pi, and other DIY components, as well as provider-subsided mobile phones, the requirement for equipment does not necessarily mean expensive. This argument is further underscored by the complexity and presumable price of equipment-free, disposable all-in-one cartridgetype diagnostics. While such cartridge-based diagnostics may provide a promising option for unmet needs in countries where governments and health insurance cover the cost, global health applications are not likely able to bear the cost even when concessional prices are applied [49]. Thus, for now, we advocate for the research and development of diagnostics that seek a balance between high-quality results and cost through minimal equipment workflows, rather than equipment-free solutions alone.

\subsubsection{Paper-Based Devices}

Clever designs based on paper are serving to miniaturize some of these equipmentdependent steps into compact and inexpensive devices. Paper is a simple material and inexpensive to manufacture and its intrinsic capillary force moves liquids without the need of pump, batteries, or an external power source. Lateral flow assays, like the pregnancy test, are the most common commercial examples of where paper fulfills such a role. They provide robust and reliable performance, but are limited to a single diagnostic function and are not easily adapted to complex multistep processes. However, as we have discussed throughout the chapter, innovative researchers are extending paper materials to these more complex tasks. In an early example of this, Martinez and colleagues developed a 3D microfluidic paper analytical device ( $\mu \mathrm{PAD}$ ) by stacking layers of wax-patterned paper to allow for more complex molecular processes and multiplexing (fluid distribution into arrays with $>1000$ zones) while keeping simplicity in fabrication and cost low [144]. Wang et al. [145] developed a "pop-up" device from a folded single sheet of paper, enabling sequential control of the timing and the fluidic path.

There are also the origami devices mentioned earlier that enable complex processes like sample preparation [73]. Moreover, paper has found its way into hybrid devices where it is embedded into plastic channels as fluidic media for instrumentfree use [107]. Here the addition of water and the action of folding allowed the sequential delivery of dry-stored reagents to diagnostic samples. Another creative approach has taken advantage of another cellulose-based commodity, cotton thread. Here Zhou and colleagues [146] developed an immunoassay on threads allowing 
multiplexing as well as quantification of the analyte. So by simply stacking, weaving, folding, or unfolding the paper/cellulose, creative 3D devices can reduce dependence for equipment by mediating sequential organization and control over sample preparation and/or detection.

\subsubsection{Paper Digital Microfluidics}

Digital microfluidics (DMF) will be a key disruptive technology for POC diagnostics on the path to minimal equipment and equipment-free workflows. Just as molecular technologies and nanomaterials promise to replace equipment by providing lower temperature diagnostic regimes and signal amplification, DMF promises to dramatically simplify low-cost fluid handling and automation of complexity. Through an array of patterned electrodes, DMF uses the application of an electrical field to dispense, move, and mix microdroplets (pico- to microliters) in a chip [147]. While most microfluidic devices rely on external pressure sources, pumps, continuous flow, and large amount of samples or reagents, DMF technology enables savings in reagents, sample, and therefore cost. In 2004, Srinivasan et al. [148] were able to actuate by electrowetting, human physiological samples like whole human blood, serum, plasma, urine, saliva, sweat, and tear as well as perform a glucose assay. The flexibility of DMF enables functions like sample separation and extraction, for example, with the use of mixing areas with lytic agents or heating zone on a single device. In 2009 Mousa et al. [149] successfully separated and extracted estradiol from breast tissue, whole blood, and serum and in $2015 \mathrm{Ng}$ et al. [150] presented a proof of concept for the use of DMF as a diagnostic platform for detection of infectious diseases. The demonstration was performed with a fully integrated sample preparation for the detection of rubella infection. The shoeboxsized automated platform was able to aliquot, dilute, and multiplex four parallel assays as well as deliver an automated digital readout of the assay. Recent work has combined DMF with paper (paper-DMF) to create cheap, fast, complex, and multiplexed diagnostic devices [151] using conductive silver ink on paper.

What is especially exciting about the technology is that it is adaptive. A common electrode array can be reprogrammed after manufacturing to execute virtually any of the steps in the diagnostic workflow. All of the reagents necessary for sample preparation and analysis can be incorporated into the device, along with the preprogrammed sequence of droplet movement. Thus, the paper-DMF platform can provide sequential flow of the sample and reagents, as well as complex multistep processes, without any intervention of the user. Importantly, recent advances in the manufacture of DMF devices, with roll-to-roll production, have brought device cost down to $\$ 0.63$ USD per chip [152]. Finally, a device called the DropBot has recently been released as an open-source platform for controlling droplet actuation in DMF [153]. Open-source hardware and software is an important new trend for diagnostics that allows anyone to build and modify companion devices for their own needs. So 
while paper-DMF is indeed instrumented, with such impressive capabilities and economics, we will likely see DMF technology embedded in many future POC diagnostics.

\subsection{Future of the Technology}

With the future of diagnostic technologies in mind, we asked ourselves where is paper-based device technology heading. What can we expect from the field in the next years? Based on the current literature, we propose a "what if" list of what could the technology become.

"What if" paper-based devices allowed:

- Together with the massive development of wearable electronics like watches, and even clothing (like Cityzen sciences or Hexoskin, among others), sensors that monitor vital signs are starting to be found in everyday life. Güder and colleagues recently developed a smart paper that functions as a low-cost electrical respiration sensor that is able to transmit data concerning respiration to a smartphone [154]. So "what if" smart papers were the new low-cost technology allowing routine monitoring of vital signs and other clinical features in individuals admitted to the hospital?

- Understanding and consent of the populations for research is an important challenge facing the research community. However, as paper-based diagnostic capabilities grow, an automated, anonymized electronic reporting becomes possible, and "what if" paper devices could allow large epidemiological studies through citizen science? Such studies could be health related, but they could also aid with monitoring disease vectors (e.g., ducks for influenza), environmental factors, etc. [89, 155].

- "What if" paper devices (low-cost technology) and citizen science could make a shift from responding to illness to anticipating disease with early detection and health monitoring?

- Recent work reports electrically activated paper actuators that fold and bend in response to an applied current [156]. "What if" paper-based diagnostic devices could move on their own, following a preprogrammed sequence of movements, to complete a diagnostic workflow from sample collection to the delivery of the result?

- In 2013, Safavieh and Juncker introduced the term of Capillarics, a preprogrammed, self-powered microfluidic circuit built from capillary elements where liquid handling is encoded in the structure and chemistry of the conduits [157]. "What if" paper-based devices could be similarly self-powered through careful design of their materials?

- "What if" paper-based devices, thanks to their low-cost technology and production, could permit the development of a more accessible type of personalized medicine? 
- But maybe the most important point: "What if" POC diagnostic devices were designed and developed for a specific problem and in collaboration with end users? This could improve the ratio of devices capable of success at the POC. In a paper by Kumar and colleagues, two case studies exemplify the potential benefit of this approach and highlight the technical and operational lessons provided by such community-based partnerships [11].

\subsection{Conclusion}

Looking back over the contents of the book we are struck by the pace, scale, and diversity of ongoing work, as well as the realization that the field of POC diagnostics has grown beyond a scope that can be mastered by any one technique or investigator. This of course is exciting, but also daunting, for researchers as they seek to advance the field. The ASSURED criteria will provide ongoing guidance to the development of relevant tools, but of course it is important to recognize that each design feature should be considered in the context of the intended POC environment. In other words, the intended application of an ideal diagnostic device must be considered from the outset of design. When cost is not the main limiting factor to deployment, ultrarapid, self-contained disposable cassettes may be ideal. However in well-established but poor urban environments, other factors such as time or convenience may be less of a constraint on design in favor of being able to provide clinical-grade results. There may even be a future for applications where even sensitivity or specificity can be sacrificed in favor of strategies in which multiplexed detection and low cost provide redundancy for diagnosis of complex disease (e.g., paper-based gene expression profiling; [158]). The key is that without a final set of applications and target population in mind, the complete design space available to build practical portable diagnostics may not be recognized (Fig. 6.1).

Similarly, as developers of POC diagnostics we must also be held to account on implementation, including a workflow from sample through to answer. Steps toward implementation must follow technology development; otherwise our efforts become only an academic exercise, which must not happen. Unfortunately, the literature is replete with reports of incremental advances that have not been demonstrated with real samples and/or under real-field conditions. While the reasons for this are complex, future leaders in the field, and those who will see their designs catch the attention of the funders, will be the ones who take the time (and risk) to push the limits of their technology and iterate until their design criteria are met. This may require a series of studies and vertical integration of our laboratory efforts, but the responsibility is on us to demonstrate the value of our work at point of care.

Other trends that will continue to be important to the advancement of our field will be the adoption and adaptation of disruptive technologies from other areas of study. The field is built upon this approach and as we seek to extend our tools to new populations, environments, and clinical needs, we will need to continue to combine these innovations into our designs. Technologies that we see as key areas 


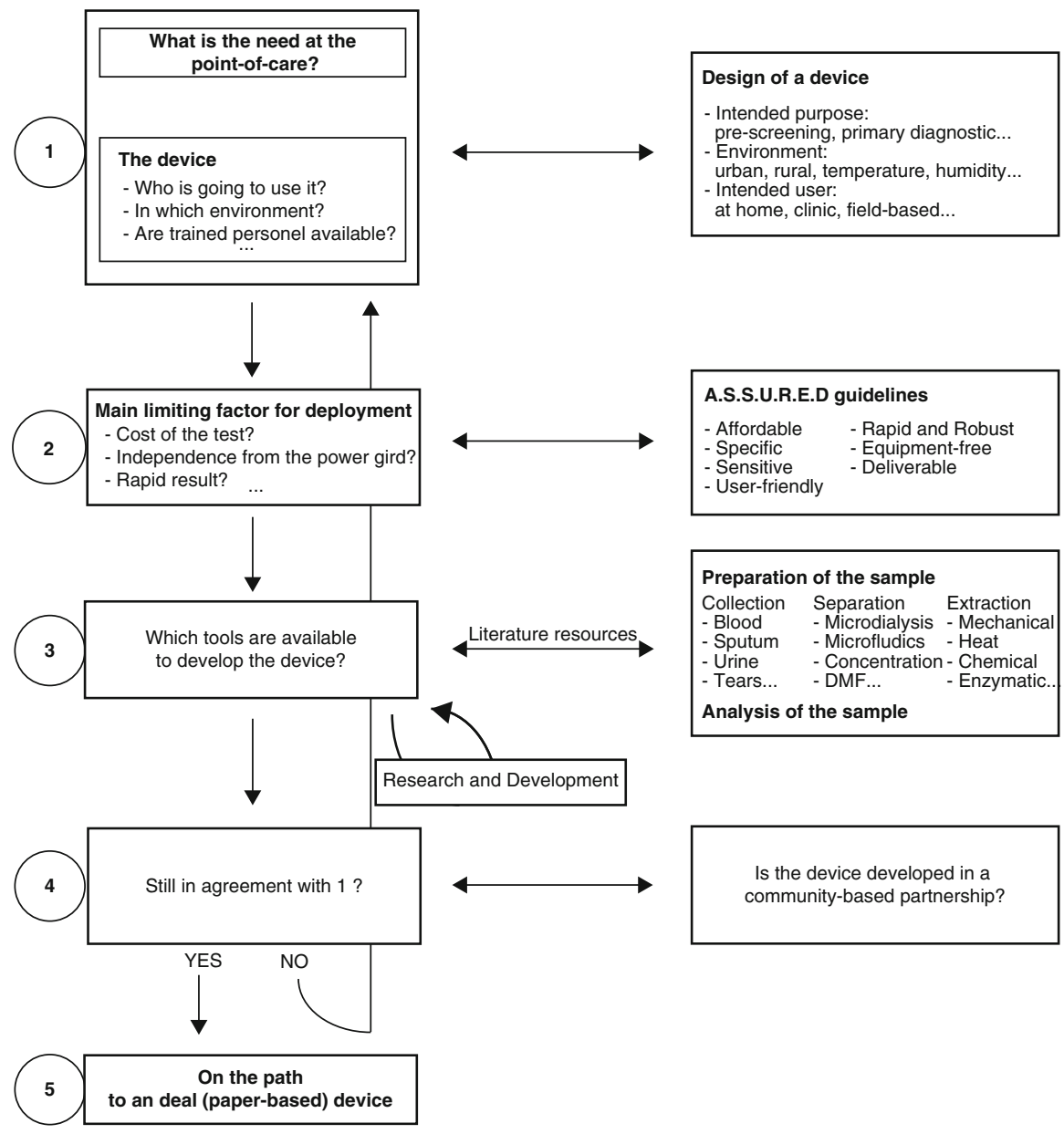

Fig. 6.1 Design of an ideal (paper-based) device workflow. The successful design and implementation of paper-based diagnostics require a holistic view that considers the goals of the test, the limitations in the intended environment for its use, and the context of the sample from which it will be expected to perform. This technical design and development must also be paired with partnerships at the community level and, ultimately, tested under field conditions

to watch are the following. (1) Sample preparation technologies that are portable and cost effective are perhaps the most critical to the success of our field as well as the compatibility of the preparation, extraction, and analysis steps. It is this capability that will convert innovative assays into field-ready tools. Here we see digital/microfluidics as key to implementing low-cost and automated workflows that can be used by nonexperts under field conditions. (2) Nucleic acid amplification and other molecular technologies will be an increasing source of capability for POC diagnostics as researchers incorporate new techniques and enzymes, as well 
as methods for deployment without refrigeration. (3) Materials engineering and nanotechnologies will also provide exciting and increasingly cost-effective ways of moving laboratory assays to the field.

Taken together, the merging of new sensor technologies with the incredible advances in materials, electronics, and telecommunications suggests that the field of POC diagnostics is on the verge of a revolution. This potential boon in capabilities could not come at a better time. The human population is growing at a rate of 1.6 million every week, and so, with such growth, our ability to provide timely access to health care will increasingly depend on distributed care through portable tools of diagnosis. Moreover, this drive to reduce cost and extend access to health care is something that will be globally beneficial and our challenge as a field will be how to meet such diverse needs. And it is through this lens that we suggest that the journey to the ideal device(s) has many paths.

\section{References}

1. Yagoda H (1937) Applications of confined spot tests in analytical chemistry: preliminary paper. Ind Eng Chem Anal Ed 9:79-82

2. Davies RJ, Eapen SS, Carlisle SJ (2008) Lateral-flow Immunochromatographic assays. In: Handbook of biosensors and biochips. John Wiley \& Sons, Ltd, New Jersey

3. Anderson CE, Shah KG, Yager P (2017) Sensitive protein detection and quantification in paper-based microfluidics for the point of care. Methods Enzymol 589:383-411

4. Sia SK, Linder V, Parviz BA, Siegel A, Whitesides GM (2004) An integrated approach to a portable and low-cost immunoassay for resource-poor settings. Angew Chem Int Ed 43:498 502

5. Martinez AW, Phillips ST, Butte MJ, Whitesides GM (2007) Patterned paper as a platform for inexpensive, low-volume, portable bioassays. Angew Chem Int Ed 46:1318-1320

6. WHO (2004) TDR/Mapping the landscape of diagnostics for sexually transmitted infections [WWW Document]. WHO. http://www.who.int/tdr/publications/tdr-research-publications/ mapping-landscape-sti/en/. Accessed 7 July 2017

7. Brehm-Stecher B, Young C, Jaykus L-A, Tortorello ML (2009) Sample preparation: the forgotten beginning. J Food Prot 72:1774-1789

8. Mariella R (2008) Sample preparation: the weak link in microfluidics-based biodetection. Biomed Microdevices 10:777-784

9. Niemz A, Ferguson TM, Boyle DS (2011) Point-of-care nucleic acid testing for infectious diseases. Trends Biotechnol 29:240-250

10. Tang RH, Yang H, Choi JR, Gong Y, Feng SS, Pingguan-Murphy B, Huang QS, Shi JL, Mei $\mathrm{QB}, \mathrm{Xu} \mathrm{F}$ (2016) Advances in paper-based sample pretreatment for point-of-care testing. Crit Rev Biotechnol 1-18

11. Kumar AA, Hennek JW, Smith BS, Kumar S, Beattie P, Jain S, Rolland JP, Stossel TP, Chunda-Liyoka C, Whitesides GM (2015) From the bench to the field in low-cost diagnostics: two case studies. Angew Chem Int Ed Engl 54:5836-5853

12. Anderson NL, Anderson NG (2002) The human plasma proteome: history, character, and diagnostic prospects. Mol Cell Proteomics 1:845-867

13. Obermoser G, Presnell S, Domico K, Xu H, Wang Y, Anguiano E, Thompson-Snipes L, Ranganathan R, Zeitner B, Bjork A, Anderson D, Speake C, Ruchaud E, Skinner J, Alsina L, Sharma M, Dutartre H, Cepika A, Israelsson E, Nguyen P, Nguyen Q-A, Harrod AC, Zurawski SM, Pascual V, Ueno H, Nepom GT, Quinn C, Blankenship D, Palucka K, Banchereau J, 
Chaussabel D (2013) Systems scale interactive exploration reveals quantitative and qualitative differences in response to influenza and pneumococcal vaccines. Immunity 38:831-844

14. Robison EH, Mondala TS, Williams AR, Head SR, Salomon DR, Kurian SM (2009) Whole genome transcript profiling from fingerstick blood samples: a comparison and feasibility study. BMC Genomics 10:617

15. Paliwal S, Hwang BH, Tsai KY, Mitragotri S (2013) Diagnostic opportunities based on skin biomarkers. Eur J Pharm Sci 50:546-556

16. Fernando GJP, Chen X, Prow TW, Crichton ML, Fairmaid EJ, Roberts MS, Frazer IH, Brown LE, Kendall MAF (2010) Potent immunity to low doses of influenza vaccine by probabilistic guided micro-targeted skin delivery in a mouse model. PLoS One 5:e10266

17. Matriano JA, Cormier M, Johnson J, Young WA, Buttery M, Nyam K, Daddona PE (2002) Macroflux microprojection array patch technology: a new and efficient approach for intracutaneous immunization. Pharm Res 19:63-70

18. Prausnitz MR (2004) Microneedles for transdermal drug delivery. Adv Drug Deliv Rev 56:581-587

19. Wang PM, Cornwell M, Prausnitz MR (2005) Minimally invasive extraction of dermal interstitial fluid for glucose monitoring using microneedles. Diabetes Technol Ther 7:131141

20. Corrie SR, Fernando GJP, Crichton ML, Brunck MEG, Anderson CD, Kendall MAF (2010) Surface-modified microprojection arrays for intradermal biomarker capture, with low nonspecific protein binding. Lab Chip 10:2655-2658

21. Lee KT, Muller DA, Coffey JW, Robinson KJ, McCarthy JS, Kendall MAF, Corrie SR (2014) Capture of the circulating Plasmodium falciparum biomarker HRP2 in a multiplexed format, via a wearable skin patch. Anal Chem 86:10474-10483

22. Matriano JA, Cormier MJN (2004). Method for transdermal nucleic acid sampling. US6749575 B2

23. Aas JA, Paster BJ, Stokes LN, Olsen I, Dewhirst FE (2005) Defining the normal bacterial Flora of the oral cavity. J Clin Microbiol 43:5721-5732

24. Muzanye G, Morgan K, Johnson J, Mayanja-Kizza H (2009) Impact of mouth rinsing before sputum collection on culture contamination. Afr Health Sci 9:200

25. Boehme CC, Nabeta P, Hillemann D, Nicol MP, Shenai S, Krapp F, Allen J, Tahirli R, Blakemore R, Rustomjee R, Milovic A, Jones M, O'Brien SM, Persing DH, Ruesch-Gerdes S, Gotuzzo E, Rodrigues C, Alland D, Perkins MD (2010a) Rapid molecular detection of tuberculosis and rifampin resistance. N Engl J Med 363:1005-1015

26. Ferguson TM, Weigel KM, Lakey Becker A, Ontengco D, Narita M, Tolstorukov I, Doebler R, Cangelosi GA, Niemz A (2016a) Pilot study of a rapid and minimally instrumented sputum sample preparation method for molecular diagnosis of tuberculosis. Sci Rep 6:19541

27. Chanda-Kapata P, Kapata N, Klinkenberg E, Grobusch MP, Cobelens F (2017) The prevalence of HIV among adults with pulmonary TB at a population level in Zambia. BMC Infect Dis $17: 236$

28. Perkins MD, Cunningham J (2007) Facing the crisis: improving the diagnosis of tuberculosis in the HIV era. J Infect Dis 196:S15-S27

29. Mansuy JM, Mengelle C, Pasquier C, Chapuy-Regaud S, Delobel P, Martin-Blondel G, Izopet $\mathrm{J}$ (2017) Zika virus infection and prolonged Viremia in whole-blood specimens. Emerg Infect Dis 23:863-865

30. Barzon L, Pacenti M, Berto A, Sinigaglia A, Franchin E, Lavezzo E, Brugnaro P, Palù G (2016) Isolation of infectious Zika virus from saliva and prolonged viral RNA shedding in a traveller returning from the Dominican Republic to Italy, January 2016. Eur Secur 21:30159

31. Atkinson B, Hearn P, Afrough B, Lumley S, Carter D, Aarons EJ, Simpson AJ, Brooks TJ, Hewson R (2016) Detection of Zika virus in semen. Emerg Infect Dis 22:940

32. Mansuy JM, Dutertre M, Mengelle C, Fourcade C, Marchou B, Delobel P, Izopet J, MartinBlondel G (2016) Zika virus: high infectious viral load in semen, a new sexually transmitted pathogen? Lancet Infect Dis 16:405 
33. Panpradist N, Toley BJ, Zhang X, Byrnes S, Buser JR, Englund JA, Lutz BR (2014) Swab sample transfer for point-of-care diagnostics: characterization of swab types and manual agitation methods. PLoS One 9:e105786

34. Huang S, Abe K, Bennett S, Liang T, Ladd PD, Yokobe L, Anderson CE, Shah K, Bishop J, Purfield M, Kauffman PC, Paul S, Welch AE, Strelitz B, Follmer K, Pullar K, Sanchez-Erebia L, Gerth-Guyette E, Domingo GJ, Klein E, Englund JA, Fu E, Yager P (2017) Disposable autonomous device for rapid swab-to-result diagnosis of influenza. Anal Chem

35. Liu C, Mauk M, Gross R, Bushman FD, Edelstein PH, Collman RG, Bau HH (2013) Membrane-based, sedimentation-assisted plasma separator for point-of-care applications. Anal Chem 85:10463-10470

36. Son JH, Lee SH, Hong S, Park S, Lee J, Dickey AM, Lee LP (2014) Hemolysis-free blood plasma separation. Lab Chip 14:2287-2292

37. Chatterjee A, Mirer PL, Zaldivar Santamaria E, Klapperich C, Sharon A, Sauer-Budge AF (2010) RNA isolation from mammalian cells using porous polymer monoliths: an approach for high-throughput automation. Anal Chem 82:4344-4356

38. Song S, Singh AK, Kirby BJ (2004) Electrophoretic concentration of proteins at laserpatterned nanoporous membranes in microchips. Anal Chem 76:4589-4592

39. Zhu L, Zhang Q, Feng H, Ang S, Chau FS, Liu W-T (2004) Filter-based microfluidic device as a platform for immunofluorescent assay of microbial cells. Lab Chip 4:337-341

40. Van der Bruggen B, Mänttäri M, Nyström M (2008) Drawbacks of applying nanofiltration and how to avoid them: a review. Sep Purif Technol 63:251-263

41. Byrnes SA, Bishop JD, Lafleur L, Buser JR, Lutz B, Yager P (2015) One-step purification and concentration of DNA in porous membranes for point-of-care applications. Lab Chip 15:2647-2659

42. D’Amico L, Ajami NJ, Adachi JA, Gascoyne PRC, Petrosino JF (2017) Isolation and concentration of bacteria from blood using microfluidic membraneless dialysis and dielectrophoresis. Lab Chip 17:1340-1348

43. Walker GM, Beebe DJ (2002) An evaporation-based microfluidic sample concentration method. Lab Chip 2:57-61

44. Wong SY, Cabodi M, Rolland J, Klapperich CM (2014) Evaporative concentration on a paperbased device to concentrate analytes in a biological fluid. Anal Chem 86:11981-11985

45. Choi K, Boyacı E, Kim J, Seale B, Barrera-Arbelaez L, Pawliszyn J, Wheeler AR (2016) A digital microfluidic interface between solid-phase microextraction and liquid chromatography-mass spectrometry. J Chromatogr A 1444:1-7

46. Allen V, Nicol MP, Tow LA (2016) Sputum processing prior to Mycobacterium tuberculosis detection by culture or nucleic acid amplification testing: a narrative review. Res Rev J Microbiol Biotechnol 17(Suppl 1):69

47. Boehme CC, Nicol MP, Nabeta P, Michael JS, Gotuzzo E, Tahirli R, Gler MT, Blakemore R, Worodria W, Gray C, Huang L, Caceres T, Mehdiyev R, Raymond L, Whitelaw A, Sagadevan K, Alexander H, Albert H, Cobelens F, Cox H, Alland D, Perkins MD (2011) Feasibility, diagnostic accuracy, and effectiveness of decentralised use of the Xpert MTB/RIF test for diagnosis of tuberculosis and multidrug resistance: a multicentre implementation study. Lancet 377:1495-1505

48. Mirzayev F (2012) Current dynamics in the Xpert MTB/RIF assay pricing mechanisms [WWW Document]. http://www.stoptb.org/wg/gli/assets/html/day\%202/Mirzayev\%20\%20Xpert\%20cartridge\%20price\%20dynamics.pdf. Accessed 27 June 17

49. Puri L, Oghor C, Denkinger CM, Pai M (2016) Xpert MTB/RIF for tuberculosis testing: access and price in highly privatised health markets. Lancet Glob Health 4:e94-e95

50. Kim J, Johnson M, Hill P, Gale BK (2009) Microfluidic sample preparation: cell lysis and nucleic acid purification. Integr Biol (Camb) 1:574-586

51. Sambrook J, Russel DW (2001) Molecular cloning a LABORATORY MANUAL. Cold Spring Harbor, New York

52. Heiniger EK, Buser JR, Mireles L, Zhang X, Ladd PD, Lutz BR, Yager P (2016) Comparison of point-of-care-compatible lysis methods for bacteria and viruses. J Microbiol Methods 128:80-87 
53. Lee W-C, Lien K-Y, Lee G-B, Lei H-Y (2008) An integrated microfluidic system using magnetic beads for virus detection. Diagn Microbiol Infect Dis 60:51-58

54. Pardee K, Green AA, Takahashi MK, Braff D, Lambert G, Lee JW, Ferrante T, Ma D, Donghia N, Fan M, Daringer NM, Bosch I, Dudley DM, O’Connor DH, Gehrke L, Collins JJ (2016a) Rapid, low-cost detection of zika virus using programmable biomolecular components. Cell 165:1255-1266

55. Waters LC, Jacobson SC, Kroutchinina N, Khandurina J, Foote RS, Ramsey JM (1998) Microchip device for cell lysis, multiplex PCR amplification, and electrophoretic sizing. Anal Chem 70:158-162

56. Gumus A, Ahsan S, Dogan B, Jiang L, Snodgrass R, Gardner A, Lu Z, Simpson K, Erickson D (2016) Solar-thermal complex sample processing for nucleic acid based diagnostics in limited resource settings. Biomed Opt Express 7:1974-1984

57. Bera A, Herbert S, Jakob A, Vollmer W, Götz F (2005) Why are pathogenic staphylococci so lysozyme resistant? The peptidoglycan O-acetyltransferase OatA is the major determinant for lysozyme resistance of Staphylococcus aureus. Mol Microbiol 55:778-787

58. Leonard RB, Carroll KC (1997) Rapid lysis of gram-positive cocci for pulsed-field gel electrophoresis using achromopeptidase. Diagn Mol Pathol 6:288-291

59. Slifkin M, Cumbie R (1987) Serogrouping single colonies of beta-hemolytic streptococci with achromopeptidase extraction. [WWW Document]. http://jcm.asm.org/content/25/8/ 1555.short. Accessed 7 July 2017

60. Buser JR, Zhang X, Byrnes SA, Ladd PD, Heiniger EK, Wheeler MD, Bishop JD, Englund JA, Lutz B, Weigl BH, Yager P (2016) A disposable chemical heater and dry enzyme preparation for lysis and extraction of DNA and RNA from microorganisms. Anal Methods 8:2880-2886

61. Hilligoss D, Keller LM, Ramadan S, Coady J, Hellyer TJ (2011) Use of achromopeptidase for lysis at room temperature. WO2011115975 A2

62. Schilling EA, Kamholz AE, Yager P (2002) Cell Lysis and protein extraction in a microfluidic device with detection by a Fluorogenic enzyme assay. Anal Chem 74:1798-1804

63. Byrnes S, Fan A, Trueb J, Jareczek F, Mazzochette M, Sharon A, Sauer-Budge AF, Klapperich CM (2013) A portable, pressure driven, room temperature nucleic acid extraction and storage system for point of care molecular diagnostics. Anal Methods 5:3177-3184

64. Jangam SR, Agarwal AK, Sur K, Kelso DM (2013) A point-of-care PCR test for HIV-1 detection in resource-limited settings. Biosens Bioelectron 42:69-75

65. Jangam SR, Yamada DH, McFall SM, Kelso DM (2009) Rapid, point-of-care extraction of human immunodeficiency virus type 1 proviral DNA from whole blood for detection by realtime PCR. J Clin Microbiol 47:2363-2368

66. McFall SM, Wagner RL, Jangam SR, Yamada DH, Hardie D, Kelso DM (2015) A simple and rapid DNA extraction method from whole blood for highly sensitive detection and quantitation of HIV-1 proviral DNA by real-time PCR. J Virol Methods 214:37-42

67. Di Carlo D, Jeong K-H, Lee LP (2003) Reagentless mechanical cell lysis by nanoscale barbs in microchannels for sample preparation. Lab Chip 3:287-291

68. Doebler RW, Erwin B, Hickerson A, Irvine B, Woyski D, Nadim A, Sterling JD (2009) Continuous-flow, rapid Lysis devices for biodefense nucleic acid diagnostic systems. J Assoc Lab Autom 14:119-125

69. Gootenberg JS, Abudayyeh OO, Lee JW, Essletzbichler P, Dy AJ, Joung J, Verdine V, Donghia N, Daringer NM, Freije CA, Myhrvold C, Bhattacharyya RP, Livny J, Regev A, Koonin EV, Hung DT, Sabeti PC, Collins JJ, Zhang F (2017) Nucleic acid detection with CRISPR-Cas13a/C2c2. Science 356:438-442

70. ClaremontBio. OmniLyse ${ }^{\circledR}$ Lysis Cartridges $\mid$ ClaremontBio.com [WWW Document]. URL http://www.claremontbio.com/OmniLyse_Cell_Disruption_Kits_s/27.htm. Accessed 7 July 2017

71. Belgrader P, Hansford D, Kovacs GT, Venkateswaran K, Mariella R, Milanovich F, Nasarabadi S, Okuzumi M, Pourahmadi F, Northrup MA (1999) A minisonicator to rapidly disrupt bacterial spores for DNA analysis. Anal Chem 71:4232-4236 
72. Baier T, Hansen-Hagge TE, Gransee R, Crombé A, Schmahl S, Paulus C, Drese KS, Keegan H, Martin C, O’Leary JJ, Furuberg L, Solli L, Grønn P, Falang IM, Karlgård A, Gulliksen A, Karlsen F (2009) Hands-free sample preparation platform for nucleic acid analysis. Lab Chip 9:3399-3405

73. Govindarajan AV, Ramachandran S, Vigil GD, Yager P, Böhringer KF (2012) A low cost point-of-care viscous sample preparation device for molecular diagnosis in the developing world; an example of microfluidic origami. Lab Chip 12:174-181

74. Hülsheger H, Potel J, Niemann EG (1983) Electric field effects on bacteria and yeast cells. Radiat Environ Biophys 22:149-162

75. Cadossi R, Ronchetti M, Cadossi M (2014) Locally enhanced chemotherapy by electroporation: clinical experiences and perspective of use of electrochemotherapy. Future Oncol Lond Engl 10:877-890

76. Luft C, Ketteler R (2015) Electroporation knows no boundaries: the use of electrostimulation for siRNA delivery in cells and tissues. J Biomol Screen 20:932-942

77. Gao J, Yin X-F, Fang Z-L (2004) Integration of single cell injection, cell lysis, separation and detection of intracellular constituents on a microfluidic chip. Lab Chip 4:47-52

78. Ameri SK, Singh PK, Dokmeci MR, Khademhosseini A, Xu Q, Sonkusale SR (2014) All electronic approach for high-throughput cell trapping and lysis with electrical impedance monitoring. Biosens Bioelectron 54:462-467

79. Lee DW, Cho YH (2007) A continuous electrical cell lysis device using a low dc voltage for a cell transport and rupture - ScienceDirect [WWW Document]. URL http:// www.sciencedirect.com/science/article/pii/S0925400506008033. Accessed 7 July 2017

80. Wang H-Y, Banada PP, Bhunia AK, Lu C (2007) Rapid electrical lysis of bacterial cells in a microfluidic device. Methods Mol Biol 385:23-35

81. Besant JD, Das J, Sargent EH, Kelley SO (2013) Proximal bacterial lysis and detection in nanoliter wells using electrochemistry. ACS Nano 7:8183-8189

82. Lessing J, Glavan AC, Walker SB, Keplinger C, Lewis JA, Whitesides GM (2014) Inkjet printing of conductive inks with high lateral resolution on omniphobic " $R(F)$ paper" for paperbased electronics and MEMS. Adv Mater 26:4677-4682

83. Glavan AC, Christodouleas DC, Mosadegh B, Yu HD, Smith BS, Lessing J, FernándezAbedul MT, Whitesides GM (2014) Folding analytical devices for electrochemical ELISA in hydrophobic $\mathrm{R}(\mathrm{H})$ paper. Anal Chem 86:11999-12007

84. Nie Z, Nijhuis CA, Gong J, Chen X, Kumachev A, Martinez AW, Narovlyansky M, Whitesides GM (2010) Electrochemical sensing in paper-based microfluidic devices. Lab Chip 10:477-483

85. Nguyen TH, Fraiwan A, Choi S (2014) Paper-based batteries: a review. Biosens Bioelectron 54:640-649

86. Cunningham JC, DeGregory PR, Crooks RM (2016) New functionalities for paper-based sensors lead to simplified user operation, lower limits of detection, and new applications. Annu Rev Anal Chem (Palo Alto, Calif) 9:183-202

87. Gaydos C, Hardick J (2014) Point of care diagnostics for sexually transmitted infections: perspectives and advances. Expert Rev Anti-Infect Ther 12:657-672

88. Hu J, Wang S, Wang L, Li F, Pingguan-Murphy B, Lu TJ, Xu F (2014) Advances in paperbased point-of-care diagnostics. Biosens Bioelectron 54:585-597

89. Cate DM, Adkins JA, Mettakoonpitak J, Henry CS (2015) Recent developments in paperbased microfluidic devices. Anal Chem 87:19-41

90. Parolo C, de la Escosura-Muñiz A, Merkoçi A (2013a) Enhanced lateral flow immunoassay using gold nanoparticles loaded with enzymes. Biosens Bioelectron 40:412-416

91. Gerbers R, Foellscher W, Chen H, Anagnostopoulos C, Faghri M (2014) A new paper-based platform technology for point-of-care diagnostics. Lab Chip 14:4042-4049

92. Li J, Baird MA, Davis MA, Tai W, Zweifel LS, Waldorf KMA, Gale M Jr, Rajagopal L, Pierce RH, Gao X (2017) Dramatic enhancement of the detection limits of bioassays via ultrafast deposition of polydopamine. Nat Biomed Eng 1:0082

93. Ramachandran S, Fu E, Lutz B, Yager P (2014) Long-term dry storage of an enzyme-based reagent system for ELISA in point-of-care devices. Analyst 139:1456-1462 
94. Pardee K, Slomovic S, Nguyen PQ, Lee JW, Donghia N, Burrill D, Ferrante T, McSorley FR, Furuta Y, Vernet A, Lewandowski M, Boddy CN, Joshi NS, Collins JJ (2016b) Portable, on-demand biomolecular manufacturing. Cell 167:248-259.e12

95. Fu E, Liang T, Houghtaling J, Ramachandran S, Ramsey SA, Lutz B, Yager P (2011) Enhanced sensitivity of lateral flow tests using a two-dimensional paper network format. Anal Chem 83:7941-7946

96. Rohrman BA, Leautaud V, Molyneux E, Richards-Kortum RR (2012) A lateral flow assay for quantitative detection of amplified HIV-1 RNA. PLoS One 7:e45611

97. Yuan L, Hua X, Wu Y, Pan X, Liu S (2011) Polymer-functionalized silica nanosphere labels for ultrasensitive detection of tumor necrosis factor-alpha. Anal Chem 83:6800-6809

98. Nielsen K, Yu WL, Lin M, Davis SAN, Elmgren C, Mackenzie R, Tanha J, Li S, Dubuc G, Brown EG, Keleta L, Pasick J (2007) Prototype single step lateral flow technology for detection of avian influenza virus and chicken antibody to avian influenza virus. $J$ Immunoassay Immunochem 28:307-318

99. Connolly R, O'Kennedy R (2017) Magnetic lateral flow immunoassay test strip development - considerations for proof of concept evaluation. Methods San Diego Calif 116:132-140

100. Zhao Y, Chen F, Li Q, Wang L, Fan C (2015) Isothermal amplification of nucleic acids. Chem Rev 115:12491-12545

101. Chun P (2009) Colloidal gold and other labels for lateral flow immunoassays. In: Lateral flow immunoassay. Humana Press, New York

102. Du D, Wang L, Shao Y, Wang J, Engelhard MH, Lin Y (2011) Functionalized graphene oxide as a nanocarrier in a multienzyme labeling amplification strategy for ultrasensitive electrochemical immunoassay of phosphorylated p53 (S392). Anal Chem 83:746-752

103. Koczula KM, Gallotta A (2016) Lateral flow assays. Essays Biochem 60:111-120

104. Wilson R (2008) The use of gold nanoparticles in diagnostics and detection. Chem Soc Rev 37:2028-2045

105. Quesada-González D, Merkoçi A (2015) Nanoparticle-based lateral flow biosensors. Biosens Bioelectron 73:47-63

106. Ge X, Asiri AM, Du D, Wen W, Wang S, Lin Y (2014) Nanomaterial-enhanced paper-based biosensors. TrAC, Trends in Anal Chem 58:31-39

107. Fu E, Liang T, Spicar-Mihalic P, Houghtaling J, Ramachandran S, Yager P (2012a) Twodimensional paper network format that enables simple multistep assays for use in lowresource settings in the context of malaria antigen detection. Anal Chem 84:4574-4579

108. Parolo C, Medina-Sánchez M, de la Escosura-Muñiz A, Merkoçi A (2013b) Simple paper architecture modifications lead to enhanced sensitivity in nanoparticle based lateral flow immunoassays. Lab Chip 13:386-390

109. Zhang C, Zhang Y, Wang S (2006) Development of multianalyte flow-through and lateral-flow assays using gold particles and horseradish peroxidase as tracers for the rapid determination of carbaryl and endosulfan in agricultural products. J Agric Food Chem 54:2502-2507

110. Danscher G, Nørgaard JO, Baatrup E (1987) Autometallography: tissue metals demonstrated by a silver enhancement kit. Histochemistry $86: 465-469$

111. Scopsi L, Larsson LI, Bastholm L, Nielsen MH (1986) Silver-enhanced colloidal gold probes as markers for scanning electron microscopy. Histochemistry 86:35-41

112. Cho I-H, Seo S-M, Paek E-H, Paek S-H (2010) Immunogold-silver staining-on-a-chip biosensor based on cross-flow chromatography. J Chromatogr B Analyt Technol Biomed Life Sci 878:271-277

113. Horton JK, Swinburne S, O'Sullivan MJ (1991) A novel, rapid, single-step immunochromatographic procedure for the detection of mouse immunoglobulin. J Immunol Methods 140:131-134

114. Smit PW, Elliott I, Peeling RW, Mabey D, Newton PN (2014) An overview of the clinical use of filter paper in the diagnosis of tropical diseases. Am J Trop Med Hyg 90:195-210

115. Ghani AC, Burgess DH, Reynolds A, Rousseau C (2015) Expanding the role of diagnostic and prognostic tools for infectious diseases in resource-poor settings. Nature 528(7580):S50S502 
116. Curtis KA, Rudolph DL, Nejad I, Singleton J, Beddoe A, Weigl B, LaBarre P, Owen SM (2012) Isothermal amplification using a chemical heating device for point-of-care detection of HIV-1. PLoS One 7:e31432

117. Yan L, Zhou J, Zheng Y, Gamson AS, Roembke BT, Nakayama S, Sintim HO (2014) Isothermal amplified detection of DNA and RNA. Mol BioSyst 10:970-1003

118. Gan W, Zhuang B, Zhang P, Han J, Li C-X, Liu P (2014) A filter paper-based microdevice for low-cost, rapid, and automated DNA extraction and amplification from diverse sample types. Lab Chip 14:3719-3728

119. Linnes JC, Fan A, Rodriguez NM, Lemieux B, Kong H, Klapperich CM (2014) Paper-based molecular diagnostic for chlamydia trachomatis. RSC Adv 4:42245-42251

120. Craw P, Balachandran W (2012) Isothermal nucleic acid amplification technologies for pointof-care diagnostics: a critical review. Lab Chip 12:2469-2486

121. Compton J (1991) Nucleic acid sequence-based amplification. Nature 350:91-92

122. Houde A, Leblanc D, Poitras E, Ward P, Brassard J, Simard C, Trottier Y-L (2006) Comparative evaluation of RT-PCR, nucleic acid sequence-based amplification (NASBA) and real-time RT-PCR for detection of noroviruses in faecal material. J Virol Methods 135:163172

123. Liu C, Geva E, Mauk M, Qiu X, Abrams WR, Malamud D, Curtis K, Owen SM, Bau HH (2011) An isothermal amplification reactor with an integrated isolation membrane for pointof-care detection of infectious diseases. Analyst 136:2069-2076

124. Rodriguez NM, Linnes JC, Fan A, Ellenson CK, Pollock NR, Klapperich CM (2015) Paperbased rna extraction, in situ isothermal amplification, and lateral flow detection for low-cost, rapid diagnosis of influenza a (H1N1) from clinical specimens. Anal Chem 87:7872-7879

125. Vincent M, Xu Y, Kong H (2004) Helicase-dependent isothermal DNA amplification. EMBO Rep 5:795-800

126. Piepenburg O, Williams CH, Stemple DL, Armes NA (2006) DNA detection using recombination proteins. PLoS Biol 4:e204

127. Mondal D, Ghosh P, Khan MAA, Hossain F, Böhlken-Fascher S, Matlashewski G, Kroeger A, Olliaro P, Abd El Wahed A (2016) Mobile suitcase laboratory for rapid detection of Leishmania donovani using recombinase polymerase amplification assay. Parasit Vectors 9:281

128. Renner LD, Zan J, Hu LI, Martinez M, Resto PJ, Siegel AC, Torres C, Hall SB, Slezak TR, Nguyen TH, Weibel DB (2017) Detection of ESKAPE bacterial pathogens at the point of care using isothermal DNA-based assays in a portable degas-actuated microfluidic diagnostic assay platform. Appl Environ Microbiol 83:e02449-e02416

129. Teoh B-T, Sam S-S, Tan K-K, Danlami MB, Shu M-H, Johari J, Hooi P-S, Brooks D, Piepenburg O, Nentwich O, Wilder-Smith A, Franco L, Tenorio A, AbuBakar S (2015) Early detection of dengue virus by use of reverse transcription-recombinase polymerase amplification. J Clin Microbiol 53:830-837

130. Daher RK, Stewart G, Boissinot M, Bergeron MG (2016) Recombinase polymerase amplification for diagnostic applications. Clin Chem 62:947-958

131. Cordray MS, Richards-Kortum RR (2012) Emerging nucleic acid-based tests for point-of-care detection of malaria. Am J Trop Med Hyg 87:223-230

132. Green AA, Silver PA, Collins JJ, Yin P (2014) Toehold switches: de-novo-designed regulators of gene expression. Cell 159:925-939

133. Pardee K, Green AA, Ferrante T, Cameron DE, DaleyKeyser A, Yin P, Collins JJ (2014) Paper-based synthetic gene networks. Cell 159:940-954

134. van der Meer JR, Belkin S (2010) Where microbiology meets microengineering: design and applications of reporter bacteria. Nat Rev Microbiol 8:511-522

135. Slomovic S, Pardee K, Collins JJ (2015) Synthetic biology devices for in vitro and in vivo diagnostics. Proc Natl Acad Sci U S A 112:14429-14435 
136. Ostrov N, Jimenez M, Billerbeck S, Brisbois J, Matragrano J, Ager A, Cornish VW (2017) A modular yeast biosensor for low-cost point-of-care pathogen detection. Sci Adv 3:e1603221

137. IEA (2016) World Energy Outlook. https://www.iea.org/weo/newsroom/news/2016/ november/world-energy-outlook-2016.html

138. IEA (2014) Africa Energy Outlook, a focus on energy prospects in sub-saharan Africa [WWW Document]. URL https://www.iea.org/publications/freepublications/. Accessed 7 June 2017

139. GMSA Intelligence (2017) GMSA Intelligence accesses June 2017 at https:// www.gsmaintelligence.com

140. Ventures Africa (2015) $60 \%$ OF THE WORLD'S POPULATION WILL OWN A MOBILE PHONE BY 2020 accessed June 2017. http://venturesafrica.com/60-of-the-worldspopulation-will-own-a-mobile-phone-by-2020/

141. World Bank (2017) Rapid Urbanization in Africa: Investing in the Development of Africa's Cities [WWW Document]. World Bank. http://www.worldbank.org/en/news/feature/2017/ 05/02/rapid-urbanization-in-africa-investing-in-the-development-of-africas-cities. Accessed 7 June 2017

142. Lafleur LK, Bishop JD, Heiniger EK, Gallagher RP, Wheeler MD, Kauffman P, Zhang X, Kline EC, Buser JR, Kumar S, Byrnes SA, Vermeulen NMJ, Scarr NK, Belousov Y, Mahoney W, Toley BJ, Ladd PD, Lutz BR, Yager P (2016) A rapid, instrument-free, sample-to-result nucleic acid amplification test. Lab Chip 16:3777-3787

143. Yager P, Domingo GJ, Gerdes J (2008) Point-of-care diagnostics for global health. Annu Rev Biomed Eng 10:107-144

144. Martinez AW, Phillips ST, Whitesides GM (2008) Three-dimensional microfluidic devices fabricated in layered paper and tape. Proc Natl Acad Sci U S A 105:19606-19611

145. Wang C-C, Hennek JW, Ainla A, Kumar AA, Lan W-J, Im J, Smith BS, Zhao M, Whitesides GM (2016) A paper-based "pop-up" electrochemical device for analysis of betahydroxybutyrate. Anal Chem 88:6326-6333

146. Zhou G, Mao X, Juncker D (2012) Immunochromatographic assay on thread. Anal Chem 84:7736-7743

147. Choi K, Ng AHC, Fobel R, Wheeler AR (2012) Digital microfluidics. Annu Rev Anal Chem (Palo Alto, Calif) 5:413-440

148. Srinivasan V, Pamula VK, Fair RB (2004) An integrated digital microfluidic lab-on-a-chip for clinical diagnostics on human physiological fluids. Lab Chip 4:310-315

149. Mousa NA, Jebrail MJ, Yang H, Abdelgawad M, Metalnikov P, Chen J, Wheeler AR, Casper RF (2009) Droplet-scale estrogen assays in breast tissue, blood, and serum. Sci Transl Med $1: 1$ ra2

150. Ng AHC, Lee M, Choi K, Fischer AT, Robinson JM, Wheeler AR (2015) Digital microfluidic platform for the detection of rubella infection and immunity: a proof of concept. Clin Chem 61:420-429

151. Fobel R, Kirby AE, Ng AHC, Farnood RR, Wheeler AR (2014) Paper microfluidics goes digital. Adv Mater 26:2838-2843

152. Dixon C, Ng AHC, Fobel R, Miltenburg MB, Wheeler AR (2016) An inkjet printed, rollcoated digital microfluidic device for inexpensive, miniaturized diagnostic assays. Lab Chip $16: 4560-4568$

153. Fobel R, Fobel C, Wheeler AR (2013) DropBot: an open-source digital microfluidic control system with precise control of electrostatic driving force and instantaneous drop velocity measurement. Appl Phys Lett 102:193513

154. Güder F, Ainla A, Redston J, Mosadegh B, Glavan A, Martin TJ, Whitesides GM (2016) Paper-based electrical respiration sensor. Angew Chem Int Ed Engl 55:5727-5732

155. Conrad CC, Hilchey KG (2011) A review of citizen science and community-based environmental monitoring: issues and opportunities. Environ Monit Assess 176:273-291 
156. Hamedi MM, Campbell VE, Rothemund P, Güder F, Christodouleas DC, Bloch J-F, Whitesides GM (2016) Electrically activated paper actuators. Adv Funct Mater 26:2446-2453

157. Safavieh R, Juncker D (2013) Capillarics: pre-programmed, self-powered microfluidic circuits built from capillary elements. Lab Chip 13:4180-4189

158. Jenum S, Dhanasekaran S, Lodha R, Mukherjee A, Saini DK, Singh S, Singh V, Medigeshi G, Haks MC, Ottenhoff THM, Doherty TM, Kabra SK, Ritz C, Grewal HMS (2016) Approaching a diagnostic point-of-care test for pediatric tuberculosis through evaluation of immune biomarkers across the clinical disease spectrum. Sci Rep 6:18520 